CENTRE for ECONOMIC

$P$ E R F O R M A N C E

CEP Discussion Paper No 787

April 2007

\title{
The Effect of Marital Breakup on the Income Distribution of Women with Children
}

\author{
Elizabeth O. Ananat and Guy Michaels
}




\begin{abstract}
Having a female firstborn child significantly increases the probability that a woman's first marriage breaks up. Recent work has exploited this exogenous variation to measure the effect of marital breakup on economic outcomes, and has concluded that divorce has little effect on women's average household income. Employing an Abadie (2003) technique that allows us to look at the impact of marital breakup throughout the income distribution, however, we find that divorce greatly increases the probability that a woman lives in a household with income in the bottom quartile. While women partially offset the loss of spousal earnings with child support, welfare, combining households, and substantially increasing their labor supply, divorce significantly increases the odds that a woman with children is poor.
\end{abstract}

JEL Classifications: J12, J16

Keywords: marital breakup, earnings of women, poverty, children

This paper was produced as part of the Centre's Labour Markets Programme. The Centre for Economic Performance is financed by the Economic and Social Research Council.

\title{
Acknowledgements
}

We thank Daron Acemoglu, Joshua Angrist, David Autor and Jon Gruber. We also thank Alberto Abadie, Emek Basker, Victor Lavy, Gerard Padro-i-Miquel, Ebonya Washington, Yoram Weiss and participants at the labor economics and public economics workshops at MIT and the NBER Children's meetings.

Elizabeth Ananat is Assistant professor at Sanford Institute of Public Policy, Duke University. Guy Michaels is a Research Associate at the Centre for Economic Performance and Lecturer in the Economics Department, London School of Economics.

Published by

Centre for Economic Performance

London School of Economics and Political Science

Houghton Street

London WC2A $2 \mathrm{AE}$

All rights reserved. No part of this publication may be reproduced, stored in a retrieval system or transmitted in any form or by any means without the prior permission in writing of the publisher nor be issued to the public or circulated in any form other than that in which it is published.

Requests for permission to reproduce any article or part of the Working Paper should be sent to the editor at the above address.

(C) E. Ananat and G. Michaels, submitted 2007

ISBN 9780853281634 


\section{Introduction and Motivation}

The poverty rate for single mothers fell substantially between 1974 and 2002 . Over the same period, the poverty rate for married mothers remained virtually unchanged. Given these facts, one might assume that women with children are less likely to be poor than they were 30 years ago. In fact, however, the overall poverty rate for women with children rose slightly over this period, from .120 to .137 (Figure 1).

A clue to resolving this puzzle may be found in the fact that divorce and single parenthood have been increasing dramatically over the past several decades throughout the developed world. In the United States, the proportion of mothers who are single rose from about 16 percent in 1974 to roughly 26 percent in 2002 . It appears that in the absence of this trend, overall poverty rates would have decreased, rather than increased.

Current political discussions commonly assume that marriage has causal economic effects on women and children. In particular, recent welfare legislation encourages marriage as a method of increasing income and reducing the need or eligibility for welfare. President Bush's 2006 budget proposal earmarks \$1 billion of its Temporary Assistance to Needy Families (TANF, or welfare) budget for a five-year initiative "supporting healthy marriages"; ${ }^{1}$ five states allocate some of their general TANF budget to marriage promotion activities, and ten states provide cash marriage incentives in the structure of their TANF benefits. ${ }^{2}$

1 U.S. Department of Health and Human Services, "FY2006 Budget in Brief." http://www.hhs.gov/budget/06budget/acf.html 2 Gardiner, Karen, Michael Fishman, Plamen Nikolov, Asaph Glosser, and Stephanie Laud. "State Policies to Promote Marriage: Final Report." U.S. Department of Health and Human Services Assistant Secretary for Planning and Evaluation, 2002. http://aspe.hhs.gov/hsp/marriage $02 \mathrm{f} / \mathrm{report} . \mathrm{htm}$ 
Despite the assumptions made in popular debate, a causal relationship between marriage preservation and poverty reduction has not been demonstrated. Previous research has established the need for instrumental variable (IV) analysis in order to identify any effect of marital status on women's outcomes (Becker, Landes, and Michael 1977; Becker 1985; Angrist and Evans 1998; Gruber 2000). Recently, first-born child sex has emerged as an instrument for marital status, facilitating estimates of causality (Morgan and Pollard 2002, Lundberg and Rose 2003, Dahl and Moretti 2004). Using that instrument, Bedard and Deschenes (2005) conclude that "IV results cast doubt on the widely held view that divorce causes large declines in economic status for women" (p. 411). While it is true that the correlation between mean income and divorce appears to be driven by selection, we demonstrate in this paper that a conclusion based on effects at the mean is misleading. IV results, in fact, support the view that divorce greatly increases the likelihood of poverty.

This paper also uses the sex of the first-born child as an instrument for marital breakup and then conducts IV analysis to separate the causal effects of divorce from its well-known correlations. With data from the 1980 U.S. Census, we document that having a female first-born child slightly, but robustly, increases the probability that a woman's first marriage breaks up. In our sample, the likelihood that a woman's first marriage is broken is 0.63 percentage points higher if her first child is a girl, representing a 3.7 percent increase from a base likelihood of 17.2 percentage points. A discussion of the mechanisms that drive this instrument, and detailed investigations into its validity and robustness, can be found in Bedard and Deschenes (2005) and in Dahl and Moretti (2004). 
Unlike these previous papers, however, we use an Abadie (2003) IV estimation strategy that allows us to look at the impact of marital breakup throughout the income distribution. Using this technique, we find that marital breakup significantly affects the household income distribution. In particular, it dramatically increases the probability that a mother will end up with very low income.

It follows logically that divorce increases the probability of living in a household without other earners. In fact, we estimate that breakup of the first marriage greatly increases the likelihood that a woman lives in a household with less than $\$ 5000$ of annual income from others - the likelihood rises from 4 percent for those whose first marriage is intact to 46 percent for those whose first marriage breaks up.

Women can and do respond to income loss from divorce by combining with other households, through paths including remarriage or moving in with a roommate, sibling, or parents. Moreover, women further compensate through private (e.g. alimony and child support) and public (e.g. welfare) transfers, and by increasing their own labor supply. Since, further, divorce reduces family size as well as income, the net effect of the husband's departure on the household's income-to-needs ratio is ex ante ambiguous. In other words, it is therefore possible for a woman to entirely offset the loss of her husband's income so that her material well-being is undiminished.

When examining the entire income distribution, however, we find that these responses, although substantial, are often insufficient to prevent poverty. While virtually none of the women influenced by our instrument who remain in their first marriage are in poverty, nearly a quarter ( 24 percent) of those who divorce are in poverty. In fact, IV 
results suggest that divorce causes increases in poverty at least as large as those suggested by observed correlation.

We show that the lack of effect at the mean (Bedard and Deschenes 2005) comes from the fact that the cumulative distribution functions of income of women who remain married and those who divorce cross each other-we find evidence that some women who divorce, rather than moving lower in the income distribution, move towards the top of the income distribution, possibly due to strong labor and re-marriage market outcomes. We conclude that breakup of the first marriage increases the variance of income, even though there is no significant effect on the mean. Because breakup of the first marriage leads some women to have higher incomes as well as leading more women to be poor, estimates that focus on the mean do not detect the dramatic effect that divorce has on the income distribution - that, while divorce does not affect average income, it does exacerbate inequality and poverty.

After discussing our findings, we consider the potential macro implications of the relationship we identify between divorce and poverty. In recent decades, mothers' poverty rates have failed to decline as much as the overall rate. Can the increase in the proportion of divorced women in the U.S. explain this stagnation? We calculate that, in fact, the poverty rate of women with children today is substantially higher than it would be if divorce had not risen over the post-1980 period.

The paper proceeds as follows. In section 2 , we describe the data and the sample we use. In section 3, we describe the estimation strategy. In section 4, we discuss the results. In section 5, we conclude. 


\section{Data}

We use data on women living with minor children from the 5 percent 1980 Census file (Ruggles and Sobek 2003), which allow us sufficient power to identify the effect of sex of the first-born child on marital breakup. ${ }^{3}$ We limit our sample to white women who are living with all of their children, whose eldest child is under 17, who had their first birth after marriage, after age 18 and before age 45, and had a single first birth. These limitations are necessary in order to create a sample for which measurement error in the sex of the observed first-born child has a classical structure. Bedard and Deschenes (2005) take a similar although not identical approach to sample limitation, and get estimates very close to ours; Dahl and Moretti (2004) show a variety of samples, the most similar of which gives first-stage estimates that are very close to ours. For further discussion of the sample construction, see the Appendix.

\section{Estimation Framework}

In a standard IV framework, income is affected by the breakup of the first marriage, which is treated as a classic endogenous regressor:

(1) $\quad D=\alpha_{1} Z+X \alpha_{2}+U \alpha_{3}+u$

(2) $Y=\beta_{1} D+X \beta_{2}+U \beta_{3}+\varepsilon$

The right-hand-side variable of interest in equation (2), $D$, is a dummy for the breakup of the first marriage. We consider a woman as having her first marriage intact if she reported both that she was "currently married with spouse present" and that she had

\footnotetext{
${ }^{3}$ While earlier censuses have these measures, in previous decades the divorce rate was very low. Subsequent censuses, on the other hand, do not have all of the measures necessary to conduct the analysis.
} 
been married exactly once. We consider a woman as having her first marriage broken if she: has been married multiple times, is married but currently not living with her husband, is currently separated from her husband, is currently divorced, or is currently widowed. $^{4}$

Our main outcomes, $Y$, are total others' income, defined as total household income less total own income; household income; household income as a percent of the poverty line; and, in some specifications, hours worked last year. The change in others' income measures the direct effect on a woman of losing her husband's income (to the extent that the husband is not replaced by other wage earners). The change in total household income captures this direct effect but also includes the indirect effects of divorce on income: transfers from the ex-husband in the form of alimony and child support ${ }^{5}$ transfers from the state in the form of cash assistance; and income generated by changes in the woman's own labor supply. In some specifications we add these sources of income into our outcome measures sequentially. The measure of household income as a percent of the poverty line allows an adjustment for the change in need that accompanies a change in household size.

Our controls, denoted by $X$, are a vector of pre-determined demographic variables including age, age squared, age at first birth and a dummy for high-school

\footnotetext{
${ }^{4}$ We have run the analysis with ever-divorced, rather than first marriage broken, as the explanatory variable: in this case, widows and those separated from or not living with their first husband are coded as 0 rather than 1 . Our results are not sensitive to this difference in categorization.

It is not possible to systematically remove widows from the sample, since the data do not allow us to identify those whose first marriage ended in death among those who have had multiple marriages. In any event, since widowhood is endogenous to both socioeconomic status and marital duration, it is probably not desirable to exclude widows.

${ }^{5}$ The 1980 Census question reads: "Unemployment compensation, veterans' payments, pensions, alimony or child support, or any other sources of income received regularly... Exclude lump-sum payments such as money from an inheritance or the sale of a home."
} 
dropout. ${ }^{6}$ While our Ordinary Least Squares (OLS) estimates of the relationship between marital breakup and income may be sensitive to their inclusion, our IV specifications are robust to controls (results without controls are available upon request). We think of $U$ as representing unobserved factors such as human capital, views on gender roles, and taste for non-market work relative to market work and leisure. Finally, our instrumental variable, $Z$, is an indicator for having a girl as one's firstborn child.

To address concerns both about omitted variable bias and about reverse causality, we estimate equation (2) using two-stage least squares, employing the sex of the eldest child $(Z)$ as an instrument for whether the first marriage is broken $(D)$. Angrist and Imbens (1994) show that in the absence of covariates and given the standard two-stage least squares assumptions, ${ }^{7}$ the IV approach identifies the local average treatment effect:

$$
\beta_{1, I V}=\frac{\operatorname{Cov}(D, Y)}{\operatorname{Var}(D)}=\frac{E[Y \mid Z=1]-E[Y \mid Z=0]}{E[D \mid Z=1]-E[D \mid Z=0]}=E\left[Y_{1}-Y_{0} \mid D_{1}>D_{0}\right]
$$

Here $Y_{1}$ and $Y_{0}$ denote the income (or other dependent variable) for women whose first marriage is broken and intact, respectively. $D_{1}$ is an indicator for whether a woman would divorce if her first child were a girl; $D_{0}$ is an indicator for whether she would divorce if her first child were a boy. $D_{1}$ and $D_{0}$ are hypothetical constructs; in practice we can only observe the indicator for the child sex that is realized. $\beta_{1 I V}$ therefore measures the change in income due to divorce for women whose first marriage breaks up if they have a girl and remains intact if they have a boy.

\footnotetext{
${ }^{6}$ Since we look only at women who gave birth to their first child after age 19 , we can reasonably assume that the decision on whether to graduate from high school is made prior to the realization of the sex of the first-born child.

${ }^{7}$ The assumptions are: conditional independence of $Z$, exclusion of the instrument, existence of a first stage and monotonicity - see Abadie (2002). The result can be generalized for the case with covariates.
} 
However, this approach only identifies the local average treatment effect. We consider more flexible specifications in which we estimate the effect of marital breakup on the probability that a woman's income is below various thresholds. This enables us to identify the marginal effect of marital breakup on the cumulative distribution function (CDF). In addition, we obtain estimators of the CDF itself for women whose first marriage is broken and for those whose first marriage is intact. Doing so allows us to evaluate the magnitude of the effect of divorce throughout the income distribution.

To estimate the CDF, we apply a technique developed in Abadie $(2002,2003)$. Recall that the local average treatment effect formula in equation (3) gave the causal effect of treatment on the compliers, $E\left[Y_{1}-Y_{0} \mid D_{1}>D_{0}\right]$. Similarly, Abadie $(2002,2003)$ demonstrates that in absence of covariates and with the same assumptions as the standard two-stage least squares model: ${ }^{8}$

$$
E\left[Y_{0} \mid D_{1}>D_{0}\right]=\frac{E[(1-D) Y \mid Z=1]-E[(1-D) Y \mid Z=0]}{E[(1-D) \mid Z=1]-E[(1-D) \mid Z=0]}
$$

We can similarly estimate the following equation using two-stage least squares with controls, using the sex of the eldest child as an instrument:

$$
(1-D) Y=\gamma(1-D)+X \delta+\mu
$$

This strategy gives a consistent estimator:

$$
\hat{\gamma}_{I V} \rightarrow \gamma=E\left[Y_{0} \mid X ; D_{1}>D_{0}\right]
$$

\footnotetext{
${ }^{8}$ Proof of equation (4): $Z=i \Rightarrow D=D_{Z} \Rightarrow Y=Y_{Z}$ for $i=0,1$, so the numerator is: $E[(1-D) Y \mid Z=1]-E[(1-D) Y \mid Z=0]=E\left[\left(1-D_{1}\right) Y_{1}-\left(1-D_{0}\right) Y_{0}\right]$

By the monotonicity assumption this equals:

$$
E\left[\left(1-D_{1}\right) Y_{1}-\left(1-D_{0}\right) Y_{0} \mid D_{1}>D_{0}\right] P\left[D_{1}>D_{0}\right]=E\left[Y_{0} \mid D_{1}>D_{0}\right] P\left[D_{1}>D_{0}\right]
$$

Dividing by the denominator yields: $E\left[Y_{0} \mid D_{1}>D_{0}\right]$.

Since $\mathrm{X}$ is discrete, this proof can be extended to the case where we add controls.
} 
That is, $\gamma$ gives the expected value of $Y$ for compliers who have a boy (and whose marriage therefore remains intact). When we apply this method to the case where $Y$ is the CDF of the income distribution we can effectively trace out the CDF for compliers who have boys. Similarly, we could estimate the CDF for compliers who have girls. ${ }^{9}$ But a standard two-stage least squares estimate of the effect of marital breakup on an indicator for a given income level gives the difference between the two CDFs. Thus, by summing the standard coefficient and the estimate of equation (6), we can likewise trace out the CDF for compliers who have girls. Finally, we also estimate equation (6) using OLS, and compare it to the instrumental variables estimate.

\section{Results}

The first column of Table 1 gives the estimated relationship between the sex of the first-born child and marital status for our sample. We find that having a girl increases the probability of breakup of the first marriage by about 0.63 percent; due to the large sample size, this effect is measured very precisely. ${ }^{10}$ The effect of sex of the eldest child on the breakup of the first marriage is bigger than that on being currently divorced, which is 0.20 percent, because many of the women who divorced due to having a girl subsequently remarry (an endogenous response that is not properly part of our IV analysis). It is important to keep in mind that we are not estimating the effect of being

${ }^{9}$ By estimating the equation: $D Y=\theta D+X \rho+\eta$ we can get $\hat{\theta}_{I V} \rightarrow \theta=E\left[Y_{1} \mid X ; D_{1}>D_{0}\right]$. The proof is similar.

${ }^{10}$ We have also replicated this result using the Current Population Survey 1980, 1985, 1990, and 1995 Fertility Supplements, which identify the sex of a woman's actual firstborn child regardless of whether that child is still in the household, and hence require no sample restrictions. The CPS estimate of 0.68 percent is highly similar to that from our Census sample. Similarly, Bedard and Deschenes (2005), using a slightly different sample, derive an estimate of 0.80 , with a standard error of 0.10 . 
currently divorced or of residing in a mother-only household on economic outcomes. Rather, we are estimating the effect of having ever been divorced on current outcomes. Cross-sectional (OLS) regressions of the relationship between marital breakup and various measures of income and labor supply (shown in the second column of Table 1), which admit no causal interpretation, show that breakup of the first marriage is correlated with large losses in income and large increases in labor supply. These relationships confirm the conventional view that women whose first marriages end are significantly worse off than women whose first marriages remain intact.

Two-stage least squares estimates, on the other hand, suggest that the mean effect of marital breakup on material well-being is quite different from the cross-sectional results. The two-stage estimate of the effect of divorce on others' income is negative but insignificant, though still within two standard deviations of the OLS estimates, as is the two-stage estimate for log household income. The two-stage estimate of the effect of divorce on household income level, however, is significantly more positive than the OLS estimate-while the coefficient is not statistically different from zero, it is more than two standard deviations above the negative OLS estimate.

Taken together, these results imply that on average there is negative selection into divorce-women who would have had low income anyway are more likely to divorce, creating a negative cross-sectional correlation between income and divorce - and that there is no significant causal effect of divorce on mean income. These findings are all consistent with the findings of Bedard and Deschenes (2005). ${ }^{11}$

\footnotetext{
${ }^{11}$ Bedard and Deschenes (2005) concentrate on a measure they call "standardized household income," which adjusts household income for household size using guidelines from the Census Bureau. Using this measure, they find a significant positive effect of divorce on average
} 
The difference in sign between the IV estimates of the effect of divorce on mean log income and on mean level of income leads us to investigate the possibility that there are important effects of marital breakup on the income distribution, particularly at the bottom, that aren't evident at the mean. In fact, it makes intuitive sense that the effect of divorce on the income distribution would be to fatten the lower tail, rather than to shift the entire distribution uniformly downward. After all, divorce - and the implied withdrawal of the husband's income - represents a discrete fall in income. To the extent that women remarry, move in with other relatives, or have high earning potential, many may end up as well off financially as before (or even better off) — resulting in little effect of divorce on the mean of the distribution. And yet a subset of women who cannot recover from the loss could experience a much greater than average effect of divorce, and end up moving near the bottom of the distribution.

In Tables 2 and 3, the columns of results labeled "First marriage intact" report the CDF for those who remain married, estimated using the method described above. (Recall that in the two-stage least squares regressions, the CDFs are estimated for the specific group of women - "compliers"-who divorce or stay married in response to the sex of the first-born child.) The columns labeled "Difference in CDFs: broken - intact" report the estimated difference in CDFs between the compliers who have divorced and those who stay married, which is the standard coefficient on breakup in the OLS or two-stage least squares estimation.

OLS estimates of the difference in distribution of income by marital breakup (first two columns in Table 2) tell a familiar story. Divorce is associated with being much less

outcomes. In an earlier, unpublished version of that paper, however, they reported results for total household income, and, like us, found an insignificant positive effect of divorce. 
likely to have $\$ 5000, \$ 10,000, \$ 20,000$ or $\$ 30,000$ in income from others in the household; the same is true for any threshold of total household income. In cross-section, those with broken first marriages have income distributions — both household and others' - that are first-order stochastically dominated by those of women with intact first marriages. That is, divorce is correlated with a shift downward in income at every point in the income distribution. ${ }^{12}$

The two-stage least squares estimates, in the right panel of Table 2, give a more nuanced picture. ${ }^{13}$ We do in fact find a large effect of marital breakup on the probability of being at the bottom of the income distribution: women whose first marriage is broken are 42 percentage points more likely (about twelve times as likely) to have less than $\$ 5000$ in others' income, and 23 percentage points more likely (about 80 percent more likely) to have less than $\$ 10,000$. While legal transfers (which include child support and mean-tested transfers) reduce the number of compliers with no income, over a quarter of the divorced compliers have no unearned income even after accounting for transferscompared to virtually none of the compliers who stay married.

The analysis of household income, which adds in own earnings, similarly shows a large effect of marital breakup on the density at the bottom of the income distribution.

\footnotetext{
${ }^{12}$ Note also that the estimated income distribution for compliers whose first marriage remains intact is first-order stochastically dominated by the income distribution for the full sample. This result, which holds throughout Tables 4-6, is consistent with the view that the people who respond to the instrument are typically of relatively low SES.

${ }^{13}$ Note that the estimation of linear probability models results in some estimates that are slightly outside the $[0,1]$ interval, though always well within two standard errors of this interval. Despite this drawback, we prefer to follow this methodology because of its transparency.
} 
Roughly one in six of those who experience marital breakup have less than $\$ 5000$ in household income, compared to virtually none of those who remain married. ${ }^{14}$

Interestingly, the two-stage estimates also show that those who divorce due to the instrument are somewhat more likely to have income near the top of the distribution, although the differences are not statistically significant. The reversal in the sign of the difference occurs at (in the case of others' income) or below (in the case of household income) the mean of the distribution, explaining why models for the mean find little effect of marital breakup on income. Figure 2 illustrates the phenomenon. Previous literature (Mueller and Pope 1980) finds that when divorced women remarry, their second husband is typically more educated and has a higher occupational SES score. In addition, Bedard and Deschenes (2005) argue that many divorced mothers co-reside with their parents who, due to lifecycle effects, have higher incomes than their husbands did. ${ }^{15}$ The reversal in sign is more substantial for total household income than for others' income, mostly due to top-end variation in women's earnings.

The results discussed so far ignore one important aspect of divorce-namely, it reduces family size. Thus even if a woman loses income through divorce, she may not necessarily end up worse off if there are also fewer family members to support. On the other hand, if income gains at the top come heavily through combining households, the effect may be neutralized by increased family size. To estimate the effect of divorce on

\footnotetext{
${ }^{14}$ Although they cannot earn enough to make up for the loss in others' income, divorced compliers do have a very large labor supply response to the loss. Since the distributional effect on hours does not differ markedly from the mean responsiveness, a separate analysis is not included here.

${ }^{15}$ Bedard and Deschenes split their sample into those whose oldest child is under 12 years of age and those whose oldest child is 12 to 16; they find that the effect on others' income is important mostly for those with older children, who they argue are less likely to combine households. We, similarly, find that the negative effect of divorce is greater for those with older children (results available from the authors).
} 
the ratio of income to needs, we divide each woman's total household income by the poverty line for a household of that size.

As shown in Table 3, we find that changes in family size do not fully offset the effect of marital breakup on household income. The OLS estimates still indicate that marital breakup decreases normalized household income at all levels. The two-stage least squares results show that virtually none of those still in their first marriage have household income below the poverty line, while nearly a quarter of those whose first marriage ended are below poverty. Compliers whose first marriage ended are, however, significantly more likely to be above 400 percent of poverty than are compliers whose first marriage remains intact.

\section{Discussion}

Our results suggest that negative selection into divorce accounts for the observed relationship between marital breakup and lower mean income. Yet marital breakup does have a significant causal effect on the distribution of income: divorce increases the percent of women at the bottom — and perhaps at the top — tail of the income distribution. In net, divorce does cause an increase in poverty, and perhaps also inequality, for women with children.

What would have been the poverty rate of women with children in 1995 had the fraction of ever-divorced mothers not changed since 1980? In 1995 (the most recent year for which we have data on marital history from the CPS), the poverty rate for women with our sample characteristics who are still in their first marriage was 8.7 percent, while the rate for women who have ever divorced was 21.7 percent. Thus if divorce had stayed 
at its 1980 prevalence (17.2 percent ever divorced), the overall poverty rate in this sample would be:

Counterfactual poverty rate $=(\%$ ever divorced 1980$) *($ poverty rate $\mid$ ever divorced 1995$)$

$+(\%$ never divorced 1980$) *($ poverty rate $\mid$ never divorced 1995$)$

$$
=0.172 * 0.217+(1-0.172) * 0.087=0.109 \text {, }
$$

or 10.9 percent. Because the prevalence of divorce rose to 28.6 percent, the poverty rate became:

Actual poverty rate $\quad=\quad(\%$ ever divorced 1995)*(poverty rate $\mid$ ever divorced 1995) $+(\%$ never divorced 1995)*(poverty rate $\mid$ never divorced 1995) $=0.286 * 0.217+(1-0.286) * 0.087=0.124$,

or 12.4 percent. Thus the increase in divorce may potentially have caused an increase of 1.5 points, or 13.8 percent, in the poverty rate for women with our sample characteristics. If we assume that the effect holds outside of those with our sample characteristics, we can conclude that nearly 1.4 million more women and children were in poverty in 1995 than would have been if the divorce rate had remained at its 1980 level.

Our results also suggest a relationship between rising divorce and the widening of the income distribution. Previous literature has not emphasized the relationship between divorce and inequality, although both have increased substantially over the past three decades. Much of the recent literature on the causes of inequality has focused on wage inequality and the forces that may be affecting it, such as: technology (Acemoglu 2002); the decline of labor market institutions (DiNardo, Fortin, and Lemieux 1996); and the rise 
of international trade. Our findings suggest that the decline of the traditional family unit as an institution may have contributed to the rise in income inequality.

\section{Data Appendix}

The 5 percent 1980 Census data contain several measures that allow us to analyze a woman's fertility history. These include the number of children ever born to a woman, the number of marriages, the quarter as well as year of first birth, and the quarter and year of first marriage. This information permits us to identify the sex of the first-born child for most women, although not for women whose eldest child has left the household.

A substantial drawback of using cross-sectional data is the fact that we can only observe the sex of the oldest child who resides with the mother, whereas ideally we would want to observe the sex of the firstborn child. It is important that we create a sample of women for whom measurement error in the sex of the observed first-born child has a classical structure.

To that end, we attempt to restrict the sample to those women observed with all their biological children. We do so in order to limit the risk that our results will be affected by differential attrition of boys and girls. In particular, we are concerned that boys are differentially likely to end up in the custody of their fathers in the event of marital breakup. This pattern could lead to endogeneity of our instrument if the sample were left uncorrected. If, in the event of divorce, fathers keep the sons and mothers keep the daughters, there will be a spurious positive correlation in the overall sample between marital breakup and the eldest observed child being a girl. 
To address this issue, we exclude any woman for whom the number of children ever born does not equal the number of children living with her. If a mother lives with stepchildren or adopted children in a number that exactly offsets the number of her own children that are not living with her, this rule will fail to exclude her. We therefore further minimize the possibility of including women who have non-biological children "standing in" for biological children by including only women whose age at first birth is measured as between 19 and 44 .

Limiting our sample to women who live with all their children reduces the threat that differential custody rates could bias our result, but it does not eliminate this risk altogether, because we could still be more likely to include divorced women with two girls than those with one boy and one girl or those with two boys. We have tested this hypothesis, however, and find that mothers living with all their children and mothers in the overall population are equally likely to be observed with a girl as the eldest child, which suggests that sex of the eldest child is not a major determinant of living with all of one's children (results available from the authors).

Second, we limit our sample to women whose first child was born after their first marriage, since breakup of the first marriage is our focus. If instead we included out-ofwedlock births, we would be concerned that the sex of the first child affected selection into the first marriage (Lundberg and Rose 2003). To the extent that people could learn the sex of the child before it was born and thereby select into "shotgun marriages," we may still have selection into first marriage. But ultrasound technology was not yet widely used in 1980 (Campbell 2000), so this threat is not of particular concern. In addition, because we can only identify the beginning of the first marriage and not the end, 
we may include some women whose first child was born after the breakup of the first marriage. While this would weaken the first stage of our estimation, it would not bias our results.

Third, we look only at mothers whose eldest child is a minor, since those who still live with their adult children may be a select group. Further, since girls are differentially more likely to leave home early (at ages 17 and 18), we restrict to mothers whose eldest child is under age 17. Fourth, we limit our sample to white women because black women's childbearing and marital decisions may be quite different, and fully modeling the differences would greatly complicate the analysis. Finally, we leave out women whose first child was a twin, both because different-sex twins would complicate our instrument and because twins increase the number of children a woman has.

Selection into our restricted sample might be cause for concern, just as selection into the labor market is cause for concern when measuring labor outcomes. To test for such a problem, we generated the predicted probability that a woman was included in our sample based on age and birthplace dummies. Then we re-ran our two-stage estimates, treating a woman's predicted probability of inclusion as an endogenous regressor. Our first- and second-stage estimates were quite stable with and without this variable.

Table A shows summary statistics for our full sample relative to the overall population of women with minor children. Our sample is quite similar to the overall population except in terms of age and marital status. The women in our sample are younger than average, consistent with the requirement that a woman's eldest child is under 17. The women in our sample are also slightly less likely to be divorced, both because they are younger and because we require that they have custody of all children. 
And of course, unlike the overall population, women in our sample cannot be nevermarried. On other characteristics, however, the two groups differ little: women in our sample have slightly more education and household income than the overall population and work and earn slightly less.

In summary, the limitations we place on the sample are designed to create a group of women for whom we can measure the sex of the firstborn child with only classical measurement error. These restrictions weaken the power of our first stage, but we believe this compromise is necessary in order to minimize concerns about endogeneity of our instrument.

In addition to estimating our model on the full sample, we looked specifically at two subsamples that we used in specification checks: those who are at high risk of having ever divorced and those at low risk of having ever divorced. To create our high- and lowpredicted divorce subsamples, we created an exogenous risk index by predicting "ever divorced" using age, age squared, age at first birth, and dummies for place of birth and for high school dropouts (recall that our sample includes only women whose first birth occurs after age 19, so the decision on whether to graduate from high school can be treated as pre-determined). The high-risk subsample included women whose predicted risk is in the top quartile; the low-risk subsample included women whose predicted risk is in the bottom quartile. These subsamples allowed us to test our IV strategy: if the responsiveness to the child-sex instrument is proportional to the overall level of divorce, then we expect the first stage to be larger for this group. As a consequence, the two-stage effect of child sex on outcomes should also be more precise for the high-divorce subsample, if indeed our IV strategy is valid and child sex is affecting outcomes. We 
have tested this hypothesis, and that is indeed what we find (results available from the authors). 


\section{References}

Acemoglu, Daron. "Technical Change, Inequality, and the Labor Market." Journal of Economic Literature 40 (March 2002): 7-72.

Abadie, Alberto. "Semiparametric Instrumental Variable Estimation of Treatment Response Models.” Journal of Econometrics 113 (April 2003): 231-63.

------. “Bootstrap Tests for Distributional Treatment Effects in Instrumental Variable Models.” Journal of the American Statistical Association 97 (March 2002): 284292.

Angrist, Joshua D. and Evans, William S. "Children and their Parents' Labor Supply: Evidence from Exogenous Variation in Family Size.” American Economic Review 88 (June 1998): 450-477.

Angrist, Joshua D. and Imbens, Guido. "Identification and Estimation of Local Average Treatment Effects.” Econometrica 62 (March 1994): 467-476.

Becker, Gary S. "Human Capital, Effort, and the Sexual Division of Labor.” Journal of Labor Economics 3 (January 1985): S33-58.

Becker, Gary S.; Landes, Elizabeth M.; and Michael, Robert T. “An Economic Analysis of Marital Instability.” Journal of Political Economy 85 (December 1977): $1141-87$

Bedard, Kelly, and Deschenes, Olivier. "Sex Preferences, Marital Dissolution, and the Economic Status of Women.” Journal of Human Resources 40(2): 411-34, Spring 2005.

Campbell, Stuart. "History of Ultrasound in Obstetrics and Gynecology." presented at 2000 International Federation of Obstetrics and Gynecology, Washington, D.C. 
http://www.obgyn.net/avtranscripts/FIGO historycampbell.htm

Dahl, Gordon, and Moretti, Enrico. "The Demand for Sons: Evidence from Divorce, Fertility, and Shotgun Marriage.”, Working Paper No. 10281, Cambridge, MA: National Bureau of Economic Research, 2004.

DiNardo, John; Fortin, Nicole M.; and Lemieux, Thomas. "Labor Market Institutions and the Distribution of Wages, 1973-1992: A Semiparametric Approach.” Econometrica 64 (September 1996): 1001-44.

Gruber, Jonathan. "Is Making Divorce Easier Bad for Children? The Long Run Implications of Unilateral Divorce.” Working Paper no. 7968. Cambridge, MA: National Bureau of Economic Research, 2000.

Lundberg, Shelly, and Rose, Elaina. "Child Gender and the Transition to Marriage." Demography 40(2): 333-49, May 2003.

Mueller, Charles W., and Pope, Hallowell. "Divorce and Female Remarriage Mobility: Data on Marriage Matches after Divorce for White Women." Social Forces 3 (March 1980): 726-738.

Ruggles, Steven; Sobek, Matthew; et al. Integrated Public Use Microdata Series: Version 3.0. Minneapolis: Historical Census Projects, University of Minnesota, 2003 .

http://www.ipums.org

US Bureau of the Census.

http://www.census.gov/population/socdemo/hh-fam/tabMS-1.xls 


\begin{tabular}{lcccc} 
& \multicolumn{2}{c}{ First stage } & & \multicolumn{2}{c}{ Second stage } \\
\cline { 2 - 2 } Dependent variable & $\begin{array}{c}\text { Instrument: first child is a } \\
\text { girl }\end{array}$ & & OLS & 2SLS \\
\hline First marriage is broken & 0.0063 & & \\
Currently divorced & $(0.0010)$ & & \\
Ln(Household income) & 0.0020 & & \\
& $(0.0007)$ & & 0.501 & -0.230 \\
Others' income & & $(0.005)$ & $(0.437)$ \\
& & -9241 & -1041 \\
Household income & & $(42.57)$ & $(5178)$ \\
& & -5577 & 6548 \\
Hours worked last year & & $(43.41)$ & $(5570)$ \\
& & 420 & 1053 \\
& & & $(2.85)$ & $(360)$ \\
\hline
\end{tabular}

NOTE: $\mathrm{N}=619,499$. The sample includes white women who are living with all of their children, whose eldest child is under 17, who had their first birth after marriage, after age 18 and before age 45, and had a single first birth. All the regressions include the following controls: age, age squared, age at first birth and a dummy for high school dropouts. There were 4,766 observations, or about $0.77 \%$ of our observations, for which household income was zero or negative. For those observations we set $\mathrm{Ln}$ (Household income) to zero. Income is in 1980 dollars. Robust standard errors are in parentheses. 
Table 2. Cumulative Distribution of Income by Marital Status

\begin{tabular}{|c|c|c|c|c|c|}
\hline & & & & & \\
\hline Dependent Variable & & $\begin{array}{l}\text { CDF when } \\
\text { first marriage } \\
\text { is intact }\end{array}$ & $\begin{array}{l}\text { Difference in } \\
\text { CDFs: } \\
\text { broken-intact }\end{array}$ & $\begin{array}{l}\text { CDF when } \\
\text { first marriage } \\
\text { is intact }\end{array}$ & $\begin{array}{l}\text { Difference in } \\
\text { CDFs: } \\
\text { broken-intact }\end{array}$ \\
\hline Others' income & $\leq \$ 5000$ & $\begin{array}{c}0.0507 \\
(0.0003)\end{array}$ & $\begin{array}{c}0.3928 \\
(0.0014)\end{array}$ & $\begin{array}{c}0.0378 \\
(0.0785)\end{array}$ & $\begin{array}{c}0.4177 \\
(0.1202)\end{array}$ \\
\hline & $\leq \$ 10000$ & 0.1458 & 0.3850 & 0.2770 & $\begin{array}{c}0.2284 \\
0.1567)\end{array}$ \\
\hline & $<\$ 20000$ & $(0.0005)$ & $0.0015)$ & $\begin{array}{c}(0.1270) \\
0.8751\end{array}$ & $\begin{array}{l}(0.150 /) \\
-0.0416\end{array}$ \\
\hline & & $(0.0008)$ & $(0.0014)$ & $(0.1814)$ & $(0.1937)$ \\
\hline & $\leq \$ 30000$ & 0.8412 & 0.0754 & 1.0369 & -0.0821 \\
\hline & & $(0.0006)$ & $(0.0010)$ & $(0.1323)$ & $(0.1399)$ \\
\hline+ private transfers & $\leq \$ 5000$ & 0.0500 & 0.3572 & 0.0319 & 0.4110 \\
\hline & & $(0.0003)$ & $(0.0014)$ & $(0.0780)$ & $(0.1193)$ \\
\hline & $\leq \$ 10000$ & 0.1441 & 0.3667 & 0.2546 & 0.2196 \\
\hline & & $(0.0005)$ & $(0.0015)$ & $(0.1259)$ & $(0.1560)$ \\
\hline & $\leq \$ 20000$ & 0.5437 & 0.2137 & 0.8649 & -0.0608 \\
\hline & & $(0.0008)$ & $(0.0014)$ & $(0.1812)$ & $(0.1947)$ \\
\hline & $\leq \$ 30000$ & 0.8403 & 0.0714 & 1.0569 & -0.1085 \\
\hline & & $(0.0006)$ & $(0.0010)$ & $(0.1334)$ & $(0.1414)$ \\
\hline+ public transfers & $\leq \$ 5000$ & 0.0490 & 0.3418 & 0.0327 & 0.3776 \\
\hline & & $(0.0003)$ & $(0.0014)$ & $(0.0773)$ & $(0.1183)$ \\
\hline & $\leq \$ 10000$ & 0.1432 & 0.3625 & 0.2506 & 0.2222 \\
\hline & & $(0.0005)$ & $(0.0015)$ & $(0.1255)$ & $(0.1557)$ \\
\hline & $\leq \$ 20000$ & 0.5434 & 0.2114 & 0.8581 & -0.0610 \\
\hline & & $(0.0008)$ & $(0.0014)$ & $(0.1809)$ & $(0.1948)$ \\
\hline & $\leq \$ 30000$ & 0.8402 & 0.0706 & 1.0524 & -0.1108 \\
\hline & & $(0.0006)$ & $(0.0010)$ & $(0.1333)$ & $(0.1415)$ \\
\hline$(+$ own earnings $=)$ & & & & & \\
\hline household income & $\leq \$ 5000$ & 0.0294 & 0.0982 & -0.0155 & 0.1900 \\
\hline & & $(0.0005)$ & $(0.0007)$ & $(0.0603)$ & $(0.0865)$ \\
\hline & $\leq \$ 10000$ & 0.0921 & 0.1999 & 0.1502 & 0.2875 \\
\hline & & $(0.0008)$ & $(0.0010)$ & $(0.1024)$ & $(0.1312)$ \\
\hline & $\leq \$ 20000$ & 0.3994 & 0.2153 & 0.7760 & -0.2547 \\
\hline & & $(0.0013)$ & $(0.0015)$ & $(0.1806)$ & $(0.2048)$ \\
\hline & $\leq \$ 30000$ & 0.7496 & 0.0788 & 1.1079 & -0.2360 \\
\hline & & $(0.0012)$ & $(0.0013)$ & $(0.1621)$ & $(0.1729)$ \\
\hline
\end{tabular}

NOTE: $\mathrm{N}=619,499$. The sample includes white women who are living with all of their children, whose eldest child is under 17, who had their first birth after marriage, after age 18 and before age 45 , and had a single first birth. All the regressions include the following controls: age, age squared, age at first birth and a dummy for high school dropouts. Income is in 1980 dollars. Robust standard errors in parentheses. 
Table 3. Cumulative Distribution of Poverty, by Marital Status

\begin{tabular}{|c|c|c|c|c|}
\hline \multirow[b]{2}{*}{ Dependent Variable } & \multicolumn{2}{|c|}{ OLS } & \multicolumn{2}{|c|}{ 2SLS } \\
\hline & $\begin{array}{l}\text { CDF when } \\
\text { first } \\
\text { marriage is } \\
\text { intact }\end{array}$ & $\begin{array}{c}\text { Difference } \\
\text { in CDFs: } \\
\text { broken- } \\
\text { intact }\end{array}$ & $\begin{array}{l}\text { CDF when } \\
\text { first } \\
\text { marriage is } \\
\text { intact }\end{array}$ & $\begin{array}{c}\text { Difference } \\
\text { in CDFs: } \\
\text { broken- } \\
\text { intact }\end{array}$ \\
\hline \multicolumn{5}{|l|}{$\begin{array}{l}\text { Percentage of the } \\
\text { poverty threshold }\end{array}$} \\
\hline \multirow[t]{8}{*}{$\leq 100$} & 0.0565 & 0.1322 & 0.0041 & 0.2407 \\
\hline & $(0.0004)$ & $(0.0011)$ & $(0.0806)$ & $(0.1081)$ \\
\hline & 0.2224 & 0.2069 & 0.2958 & 0.2487 \\
\hline & $(0.0006)$ & $(0.0015)$ & $(0.1449)$ & $(0.1684)$ \\
\hline & 0.5051 & 0.1550 & 0.8077 & -0.1800 \\
\hline & $(0.0008)$ & $(0.0015)$ & $(0.1824)$ & $(0.2011)$ \\
\hline & 0.7349 & 0.0780 & 1.2086 & -0.4442 \\
\hline & $(0.0007)$ & $(0.0013)$ & $(0.1751)$ & $(0.1909)$ \\
\hline
\end{tabular}

NOTE: $\mathrm{N}=619,499$. The sample includes white women who are living with all of their children, whose eldest child is under 17, who had their first birth after marriage, after age 18 and before age 45, and had a single first birth. All the regressions include the following controls: age, age squared, age at first birth and a dummy for high school dropouts. Poverty is calculated using 1980 measures. Robust standard errors in parentheses. 
Demographics

Age

Years of schooling

Household income

Total own income

Weeks worked last year

Usual hours worked
All

35.1

12.0

22,747

4,905

23.9

21.1

0.802

0.040

0.085

0.215

0.043

$1,610,516$

Our sample

Currently married, spouse present

Currently separated

Currently divorced

Ever divorced

Never married

31.6

12.8

23,114

4,458

22.5

19.9

Number of observations

0.891

0.024

0.072

0.172

0.000

NOTE: First column includes all women observed in the 1980 Census living with at least one minor child. Second column includes white women who are living with all of their children, whose eldest child is under 17, who had their first birth after marriage, after age 18 and before age 45, and had a single first birth. Income is in 1980 dollars. 

Figure 1. Mothers' Poverty Rates, by Marital Status

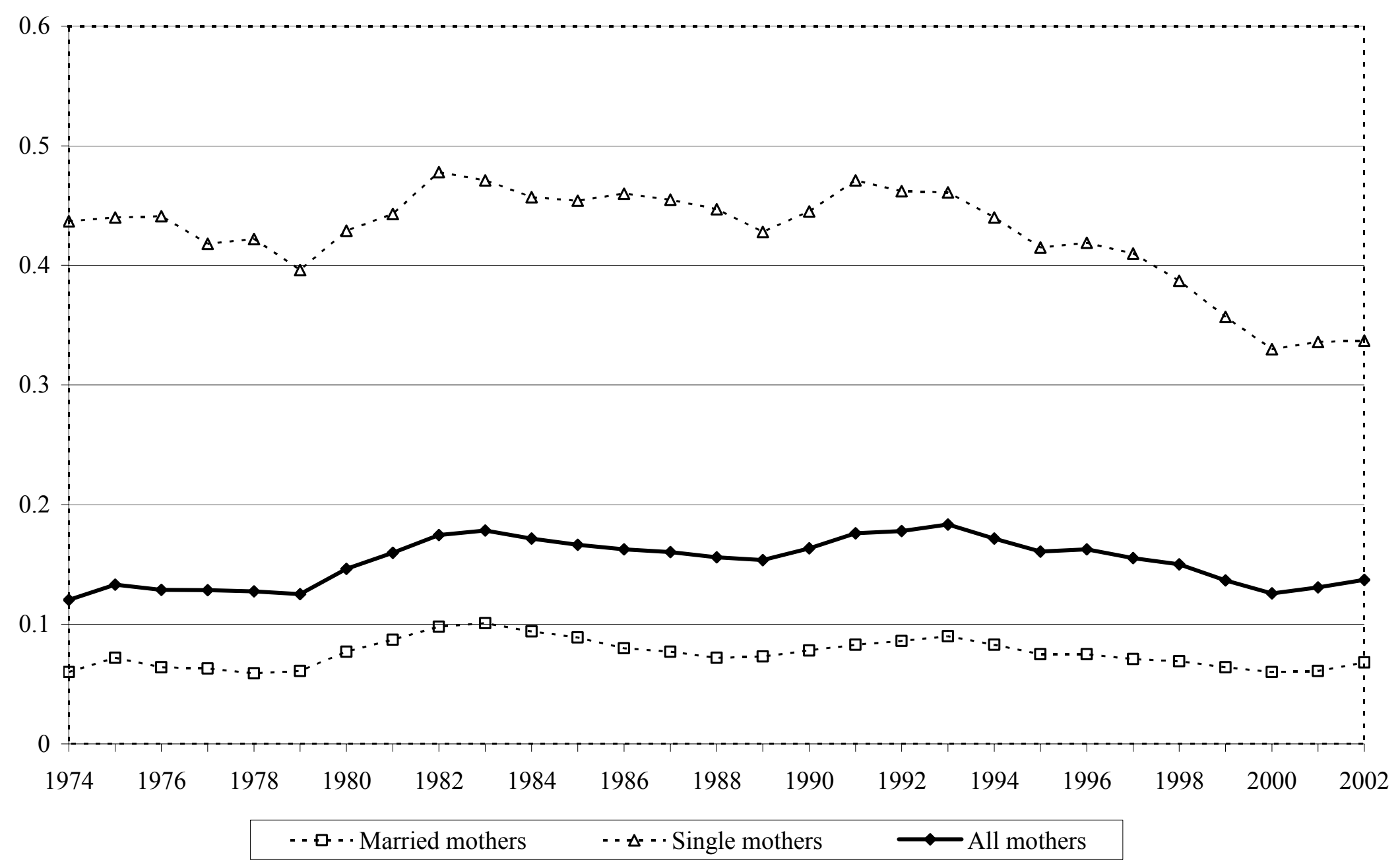


Figure 2. Cumulative Distributions of Income Sources of Women with Children, by Marital Status

I. Income of Others in the Household
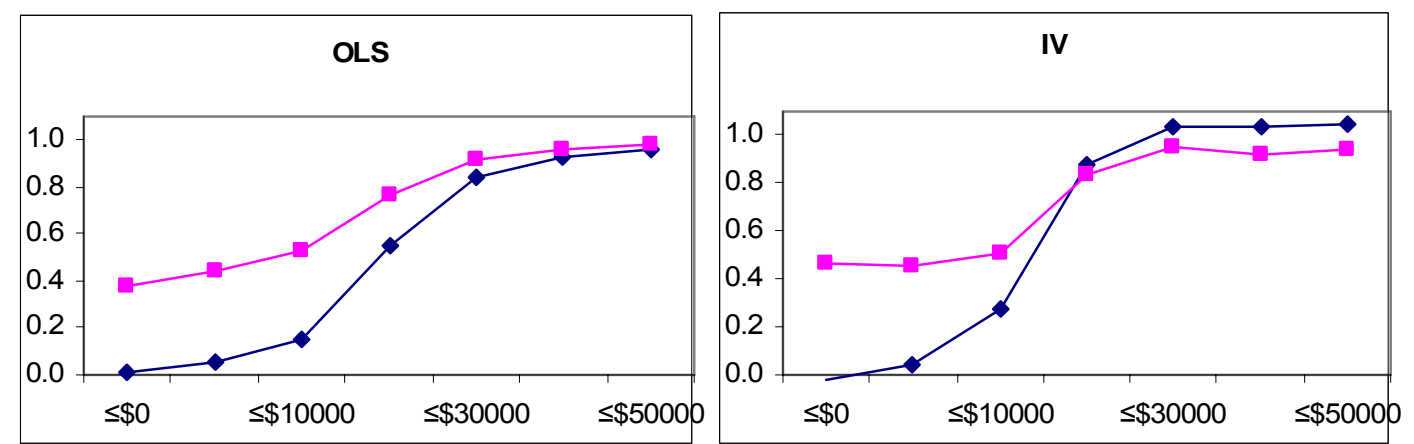

II. Total Household Income
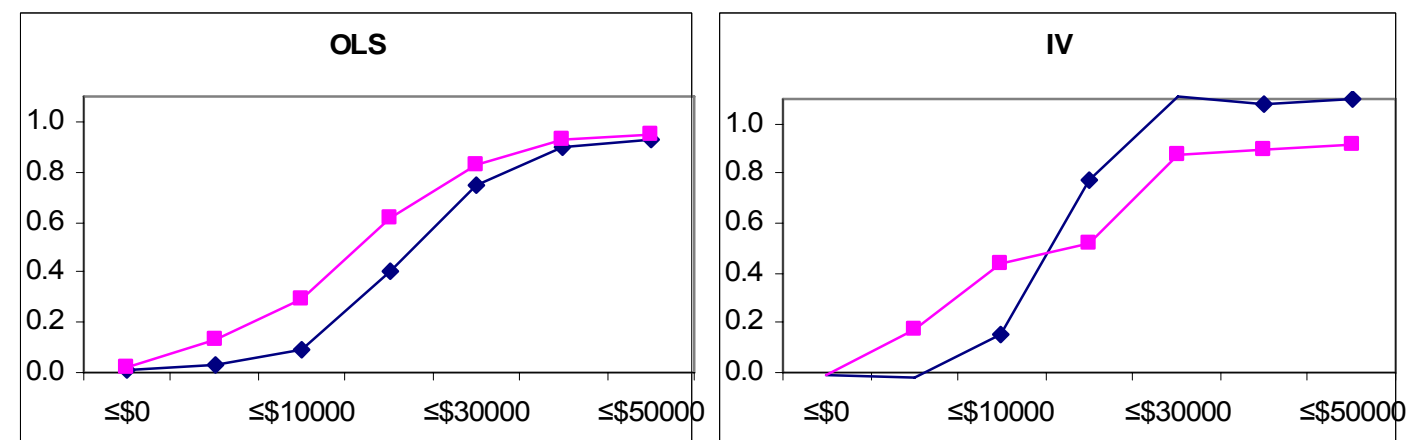

III. Household Income as a Percent of Poverty
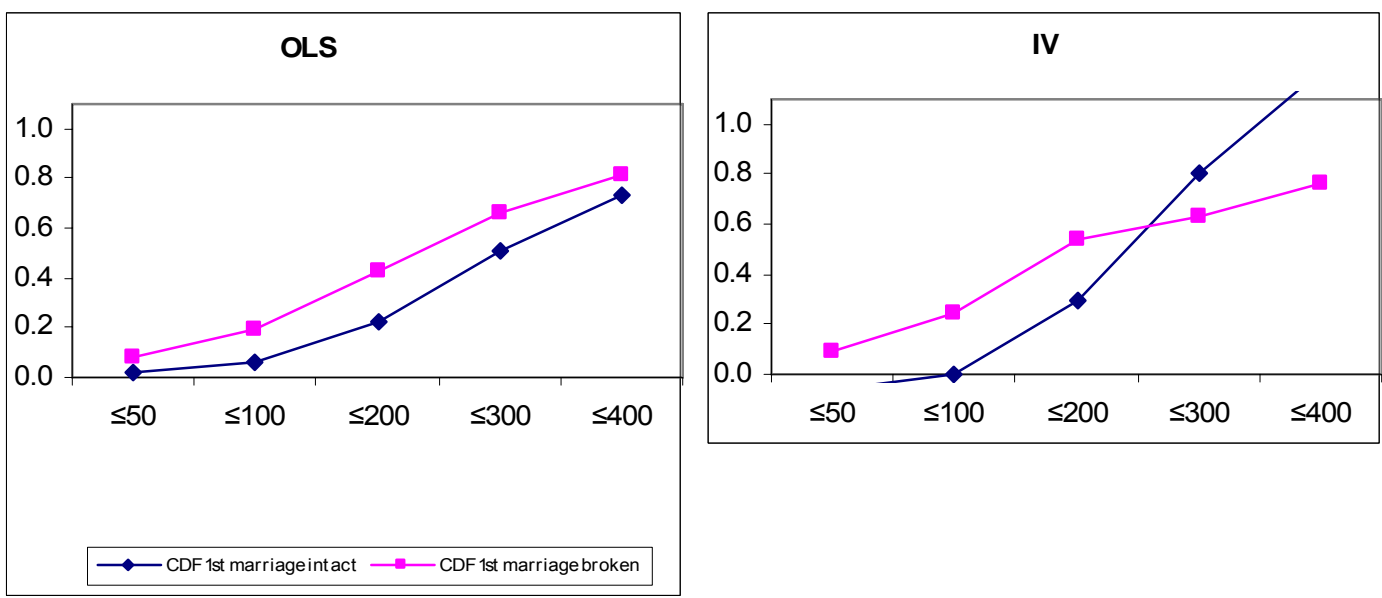


\section{CENTRE FOR ECONOMIC PERFORMANCE Recent Discussion Papers}

786 Willem H. Buiter

785 Gustavo Crespi Chiara Criscuolo Jonathan E. Haskel

Matthew Slaughter

784 Richard Layard Guy Mayraz Stephen Nickell

783 Gustavo Crespi Chiara Criscuolo Jonathan E. Haskel

782 Paul Castillo Carlos Montoro Vicente Tuesta

781 David Metcalf

780 Carlos Montoro

779 Sharon Belenzon Mark Schankerman

778 Henry G. Overman Diego Puga Matthew A. Turner

777 Florence Kondylis

776 Willem H. Buiter

775 Francesco Caselli Nicola Gennaioli

774 Paul Willman Alex Bryson

773 Alan Manning

772 Guy Michaels
Seigniorage

Productivity Growth, Knowledge Flows and Spillovers

The Marginal Utility of Income

Information Technology, Organisational Change and Productivity Growth: Evidence from UK Firms

Inflation Premium and Oil Price Volatility

Why Has the British National Minimum Wage Had Little or No Impact on Employment?

Monetary Policy Committees and Interest Rate Smoothing

Harnessing Success: Determinants of University Technology Licensing Performance

Decomposing the Growth in Residential Land in the United States

Conflict-Induced Displacement and Labour Market Outcomes: Evidence from Post-War Bosnia and Herzegovina

Is Numérairology the Future of Monetary Economics? Unbundling numéraire and medium of exchange through a virtual currency and a shadow exchange rate

Economics and Politics of Alternative Institutional Reforms

Union Organization in Great Britain Prepared for symposium for the Journal of Labor Research on "The State of Unions: A Global Perspective"

The Plant Size-Effect: Agglomeration and Monopsony in Labour Markets

The Effect of Trade on the Demand for Skill Evidence from the Interstate Highway System 
771 Gianluca Benigno

Christoph Thoenissen

770 Michael Smart

Daniel M. Sturm

769 Andrew B. Bernard

Stephen J. Redding

Peter K. Schott

768 Paul Willman

Alex Bryson

767 Anthony J. Venables

766 Guy Michaels

765 Fabrice Murtin

764 Carlo Rosa

Giovanni Verga

763 Benjamin AlemanCastilla

762 L. Rachel Ngai

Roberto M. Samaniego

761 Mariano Bosch

760 Christian Hilber Frédéric Robert-Nicoud

759 William Nickell
Consumption and Real Exchange Rates with Incomplete Markets and Non-Traded Goods

Term Limits and Electoral Accountability

Multi-Product Firms and Trade Liberalization

Accounting for Collective Action: Resource Acquisition and Mobilization in British Unions

Shifts in Economic Geography and their Causes

The Long-Term Consequences of Regional Specialization

American Economic Development Since the Civil War or the Virtue of Education

The Impact of Central Bank Announcements on Asset Prices in Real Time: Testing the Efficiency of the Euribor Futures Market

The Effect of Trade Liberalization on Informality and Wages: Evidence from Mexico

An R\&D-Based Model of Multi-Sector Growth

Job Creation and Job Destruction in the Presence of Informal Labour Markets

Owners of Developed Land Versus Owners of Undeveloped Land: Why Land Use is More Constrained in the Bay Area than in Pittsburgh

The CEP-OECD Institutions Data Set (1060-2004)

The Centre for Economic Performance Publications Unit Tel 02079557673 Fax 02079557595 Email info@cep.lse.ac.uk Web site http://cep.lse.ac.uk 